\title{
Entre dois mundos: a loucura feminina em A louca de Serrano, de Dina Salústio
}

\author{
Juliana Primi Braga*
}

\begin{abstract}
RESUMO
A literatura de autoria feminina nas sociedades pós-coloniais é considerada por Gayatri C. Spivak um processo metonímico da saga das mulheres usado como ferramenta de denúncia, que possibilita a quebra de mitos e preconceitos há muito reforçados pelo discurso patriarcal. Dentre as mulheres que encontraram sua voz e se fizeram ouvir, deixando de ser consideradas apenas informantes nativas das histórias orais de sua cultura, merecem destaque as cabo-verdianas Dina Salústio, Vera Duarte, Fátima Bettencourt, Orlanda Amarílis e Dulce Almada Duarte. O objetivo deste texto é investigar no romance A louca de Serrano, de Dina Salústio, como se constrói a temática da loucura, representada pela mulher africana e personagem Louca de Serrano, que pode ser compreendida como uma voz carregada de solidão, dor, negação, rebeldia e inconformismo e como marca de resistência à marginalização feminina nas e pelas práticas sociais hegemônicas.
\end{abstract}

Palavras-chave: Dina Salústio. A louca de Serrano. Marginalização feminina. Resistência.

[...] a loucura fascina porque é um saber. É um saber, de início, porque todas essas figuras absurdas são, na realidade, elementos de um ser difícil, fechado, esotérico. [...] Este saber, tão inacessível e temível, o Louco o detém em sua parvoíce inocente. Enquanto o homem racional e sábio só percebe desse saber algumas figuras fragmentárias - e por isso mesmo, mais inquietantes -, o Louco o carrega inteiro em uma atmosfera intacta: essa bola de cristal, que para todos está vazia, a seus olhos está cheia de um saber invisível. (FOUCAULT, 2008, p. 20-21)

Em Cabo Verde, as conquistas femininas têm sido alcançadas paulatinamente, sobretudo no que diz respeito ao princípio da igualdade de gênero apesar de as cabo-verdianas terem sido postas, por longos anos, à margem de uma sociedade que ignorava seus anseios. A independência do país (1975), cujas lutas pela

* Faculdade de Flosofia, Letras e Ciências Humanas - Univesidade de São Paulo (FFLCH/USP). 
libertação contaram com a participação ativa de muitas mulheres, dentre elas, Dulce Almada Duarte, como ressalta FERNANDES (2006), é fator contributivo para a emancipação feminina, ao outorgar o direito ao voto eleitoral.

Anos mais tarde, em 1978, forma-se a Comissão Nacional Organizadora das Mulheres de Cabo Verde - CNOMCV - e, em 1981, institui-se a Organização das Mulheres de Cabo Verde - OMCV -, organização governamental responsável por cuidar exclusivamente das questões femininas, composta por cabo-verdianas que tiveram participação no processo de luta pela autonomia do país.

Objetivando assegurar a igualdade entre homens e mulheres e anular toda distinção, restrição ou exclusão baseada no sexo, Cabo Verde adere, em 1979 (com ratificação em 1980 e em 2010), à Convenção sobre a Eliminação de Todas as Formas de Discriminação contra a Mulher - CEDAW.

Em 1984, passa a ser regimentada a Lei de Despenalização do Aborto, que, para além de suas controvérsias éticas, morais e religiosas, revela-se fulcral, ao destituir das mulheres o estigma social de criminalidade. Em 1997, o aborto seguro nas estruturas de Saúde é legalizado, por meio da Lei para a Interrupção Voluntária da Gravidez - IVG.

Com a abolição do monopartidarismo, nos anos 1990, confere-se às mulheres maior destaque através da concepção de políticas específicas no III Plano Nacional de Desenvolvimento (1992-1995), conforme descrito por Simone Caputo Gomes:

[há] maior integração das mulheres no processo de modernização da agricultura; desenvolvimento do emprego feminino e das cooperativas de mulheres; acesso ao crédito e criação de projetos de desenvolvimento para mulheres; adaptação da escola às condições socioeconômicas das mães; desenvolvimento do ensino pré-escolar como um direito da criança e forma de libertar as mães para o trabalho fora do lar; representação equilibrada nos órgãos legislativos e de decisão. (GOMES, 2008, p. 275)

A fim de dirimir as desigualdades entre homens e mulheres, é concebido o primeiro Plano de Ação Nacional de Promoção da Mulher (1996-2000). Em 1997, com o Código Civil - Livro da Família, estabelecem-se igualdades de direitos e deveres entre os cônjuges no núcleo familiar, como, por exemplo, o direito de determinar que o poder paternal deve ser exercido em conjunto pelos progenitores.

Em 2004, a violência doméstica (agressão ou maus tratos) contra as mulheres passa a ser crime punível, conforme definido pelo Código Penal (artigo 134), podendo a reclusão variar entre um e quatro anos (PEREIRA, 2013). Seis anos 
depois, diante do aumento do número de casos de violência doméstica (entre 2010 e 2011, o número duplica em 11 conselhos; entre 2011 e 2012, volta a dobrar em 9 conselhos - cf. INE/ICIEG/ONU, 2012, p. 58), o Parlamento cabo-verdiano aprova o projeto de lei ${ }^{1}$ que transforma a Violência Baseada no Gênero - VBG em crime público, ao mesmo tempo em que o país ratifica a Convenção sobre a Eliminação de Todas as Formas de Violência e Discriminação contra as Mulheres - CEDAW - e a Carta Africana dos Direitos Humanos e dos Povos.

Com o propósito de impulsionar e defender os direitos das mulheres, as organizações não governamentais ${ }^{2}$ multiplicam-se a partir dos anos 1990, cabendo destacar: a Associação de Apoio à Autopromoção da Mulher no Desenvolvimento MORABI -, de 1992; a Organização das Mulheres de Cabo Verde - OMCV -, que passa a ser ONG em 1991; a Associação das Mulheres Empresárias Profissionais de Cabo Verde - AMEPCV -, de 1992; a Associação Cabo-verdiana de Mulheres Juristas - AMJ -, de 2000; a Rede de Mulheres Parlamentares Cabo-verdianas RMP-CV -, de 2002; e a Rede de Mulheres Economistas - REDEMEC -, de 2003.

Dentre as ações e instituições criadas pelo governo, destacam-se a Comissão Nacional para os Direitos Humanos e a Cidadania - CNDHC -, de 2004, em substituição ao Comitê Nacional dos Direitos Humanos (que operou entre os anos 2001 e 2004); o Instituto Cabo-Verdiano para Igualdade e Equidade de Gênero - ICIEG -, de 2006, anteriormente designado Instituto da Condição Feminina ICF -; o Plano Nacional para Equidade e Igualdade de Gênero (2005-2011)33 e o Programa do Governo 2011-2016 para a VIII Legislatura ${ }^{4}$, o qual considera a problemática de gênero um dos 4 elementos nucleares do Programa.

No que tange à saúde das mulheres, os avanços sanitários têm colaborado para as baixas taxas de mortalidade em todas as idades. O relatório dos Objetivos do Milênio para o Desenvolvimento - 2008 (ONU/Cabo Verde ${ }^{5}$ ) considera a

1 Efetiva-se em março de 2011. Entre os anos 2010 e 2011, o número de casos de violência doméstica duplica em 11 concelhos; entre 2011 e 2012, o valor volta a dobrar em 9 concelhos (INE/ICIEG/ONU, 2012, p. 58).

2 Informações disponíveis no site Plataforma das ONGs de Cabo Verde: http://www.platongs.org.cv/ index.php?option=com_content\&view=frontpage\&Itemid=1. Acesso em 13 jun. 2013.

3 INE/ICIEG/ONU. Mulheres e homens em Cabo Verde: fatos e números 2008. Disponível em: http://www.ine.cv/actualise/publicacao/files/15c06ce8-5166-4607-ab90-1e914bc4235aMulheres\%20 e\%20Homens\%20em\%20Cabo\%20Verde.pdf. Acesso em 13 jun. 2013.

4 INE/ICIEG/ONU. Mulheres e homens em Cabo Verde: fatos e números 2012. Disponível em: http://www.ine.cv/actualise/publicacao/files/1103929942013Mulheres $\% 20 \mathrm{e} \% 20$ Homens $\% 20 \mathrm{em} \% 20$ Cabo\%20Verde.pdf. Acesso em 17 jun. 2013.

5 Disponível em: http://www.un.cv/omd.php. Acesso em 18 jun. 2013. 
mortalidade materna em Cabo Verde relativamente baixa, se comparada aos demais países da África subsaariana. O índice de mortalidade materna no país tem diminuído desde os anos 1990, sendo as principais causas de óbitos maternos eclampsia, hemorragia e gravidez extrauterina.

Sobre a saúde mental, é intenção substancial do governo de Cabo Verde que todos os portadores de distúrbios mentais e neurológicos sejam bem assistidos por especialistas e possam usufruir de tratamento especializado, com prioridade a estratégias de combate ao suicídio, à dependência tóxica, ao alcoolismo, sendo os grupos principais as crianças e os adolescentes, os deficientes, as mulheres vítimas de violência, os idosos e aqueles que vivem na linha de pobreza.

Segundo a última abordagem estatística e o mais recente estudo epidemiológico dos transtornos mentais, realizados em 1988 e 1989 e constantes do relatório dos Objetivos do Milênio para o Desenvolvimento - 2008 (ONU/Cabo Verde), havia 4,3 portadores de distúrbios mentais para cada 1000 habitantes. Em 2010, as doenças mentais e de comportamento ocupavam o $10^{\circ}$ lugar entre as causas de morte. Para prestar atendimento a esses pacientes, estão em funcionamento o Hospital Dr. Agostinho Neto, o Hospital Dr. Baptista de Sousa e alguns hospitais regionais, como o da Ribeira Grande.

A fim de defender os direitos dos cabo-verdianos que apresentem limitações na esfera da saúde mental, tem origem, em 2001, a Associação de Promoção da Saúde Mental - A PONTE -, ONG que presta assistência humanitária aos doentes e às suas famílias.

No entanto, embora haja esforços, nem sempre estes se mostram suficientes. O número de portadores de transtornos mentais que perambulam pelas ruas de Cabo Verde aumenta a cada ano, devido à insuficiência em termos de profissionais qualificados e de espaço nos hospitais. Carente de uma legislação direcionada à saúde mental, Cabo Verde aprova, em fevereiro deste ano, a proposta de lei apresentada pelo governo, que estabelece os princípios gerais de saúde mental e legitima o internamento obrigatório dos portadores de transtornos psíquicos.

No campo cultural, evidencia-se em Cabo Verde o papel das mulheres como transmissoras da sabedoria: elas intermedeiam, segundo GOMES (2008), as tradições da comunidade, os costumes, as crenças, a música - em especial, a morna, cuja principal expoente foi Cesária Évora, "a musa dos pés descalços”, morta em 2011 -, a culinária. Como os narradores de Walter Benjamin (1994), os primeiros mestres na arte de narrar, as cabo-verdianas prezam pela conservação do passado ao contar histórias para os filhos durante a noite. 
A dança aparece como uma forma de emancipação ao possibilitar que as mulheres se libertem da dominação masculina (no espaço privado) e se organizem a fim de partilhar as aflições do cotidiano (no espaço público).

A revista Claridade, cujo surgimento se dá em 1936, marca a constituição de um grupo que impacta o sistema literário cabo-verdiano, a ponto de este ser comumente periodizado em "antes, durante e depois" da Claridade. Preocupados com a realidade sociológica das ilhas, os intelectuais Manuel Lopes, Baltasar Lopes da Silva e Jorge Barbosa iniciam uma luta pela criação de uma identidade cultural autônoma.

Embora tenha havido algum empenho em abordar questões femininas, como o fez Baltasar Lopes no conto "A Caderneta", em que relata o constrangimento sofrido por uma ex-lavadeira ao tentar ocultar do médico sua atual condição de prostituta, o movimento "claridoso" foi liderado por homens e suas publicações eram quase exclusivamente escritas por homens.

A literatura cabo-verdiana feita por mulheres surge ainda discreta com a publicação da revista Mujer, incentivada pela OMCV que, entre os anos 1982 e 1984, edita 24 números, incluindo assuntos concernentes ao universo feminino específico, como amamentação, por exemplo, além de pautas culturais e políticas. Dentre as colaboradoras que produziram textos literários figuravam Vera Duarte, Lara Araújo (Madalena Tavares), Eunice Borges, Ivone Ramos e Margarida Moreira.

A dificuldade de edição no país, nos anos 1980, incita muitas escritoras a produzirem para periódicos (cf. GOMES, 2008), como é o caso de Dina Salústio, Manuela Fonseca, Ana Júlia, Alzira Pires, Helena Alhinho, dentre outras.

A antologia organizada por José Luís Hopffer Almada, Mirabilis de veias ao sol, de 1991, divulga a poesia pós-colonial de Cabo Verde, trazendo a público nomes novos como Paula Martins, Alzira Cabral, Arcília Barreto e Ana Júlia e outros já conhecidos, como Dina Salústio, Vera Duarte.

Com o romance A louca de Serrano, publicado em 1998 e o primeiro de autoria feminina em Cabo Verde, Dina Salústio conquista "a promoção de importantes rupturas na atual ficção islenha, marcando assim, de forma assaz singular, a literatura cabo-verdiana contemporânea”. (ALMADA, 2007, p. 1).

A dedicatória no início da obra - "Para Júlia, uma mulher louca que me amou mal eu tinha vivido, essa loucura de não poder esquecê-la." (SALÚSTIO, 1998, p. 7) - alerta o leitor sobre o tipo de história que encontrará: a nada comum vivência dos habitantes da enigmática e louca Serrano, uma aldeia rural esquecida da civilização. Em entrevista concedida a Genivaldo Rodrigues Sobrinho, realizada 
em Praia, 19/10/2009, na casa da autora, a nosso pedido, ela revela detalhes acerca da homenagem:

Júlia é... foi uma mulher louca, quer dizer, Júlia acompanhou um bocado da minha infância durante uns 3 anos, meus primeiros 3 anos. Quando eu nasci, a filha tinha morrido uns 15 dias antes, então, ela convenceu-se de que eu era a filha dela. Então roubavame. Como eu era gêmea com outro rapaz, eu tinha uma ama, tinha uma ama só para mim. E essa mulher que era louca, acho que ela já era louca antes de perder a filha e ela convenceu-se de que eu era a Anita. A Anita era a filha dela. E carregava-me, roubava-me, depois voltava comigo, levava-me ao cemitério, quer dizer, ela fazia-me, fazia-me não, fazia à minha mãe a vida negra. Mas eu gostava muito dela [...]. (SALÚSTIO, 2009).

Serrano, a aldeia ficcional retratada no romance, configura-se como zona de contato entre os espaços rural e urbano, suas culturas e seus discursos, a partir dos relatos de vida de seus habitantes. Além das pessoas que circulam no cotidiano da aldeia, as presenças de Fernanda/Genoveva San Martin, de seus colegas, e da equipe de reportagem de Sílvio Luxemburg, ocupada com as notícias de que "brevemente um grande complexo industrial ia ser implantado no local" (SALÚSTIO, 1998, p. 78), tornam possível a mescla de informações entre a população local e o espaço global, entre a tradição e a modernidade, aqui representada pelas imagens eternizadas em fotos.

A indefinição do espaço físico em que se desenrola a ação concede ao romance um caráter ambíguo, de estranhamento, prenunciado na caracterização da aldeia “quase bela, quase mulher, quase homem" (SALÚSTIO, 1998, p. 15) -, e refletida no teor narrativo, por vezes, cômico - "gritou para o homem mais gordo que queria anotar todas as palavras, fungadelas e suspiros do seu capitão" (SALÚSTIO, 1998, p. 20) -, por vezes, trágico, "Gremiana, a moça que se revoltou contra a aldeia e os seus costumes e tinha sido atirada às águas em dia claro que se fez escuro" (SALÚSTIO, 1998, p. 72), e nas sucessões ora contínuas, ora descontínuas dos fatos, causando dúvida a respeito do que é real, cotidiano, e o que é fantasia, imaginação, loucura, remetendo-nos ao que Todorov denomina tempo de hesitação na literatura fantástica:

O fantástico, como vimos, dura apenas o tempo de uma hesitação: hesitação comum ao leitor e à personagem, que devem decidir se o que percebem depende ou não da "realidade", tal qual existe 
na opinião comum. No fim da história, o leitor, quando não a personagem, toma, contudo, uma decisão, opta por uma ou outra solução, saindo, desse modo, do fantástico. (TODOROV, 2007, p.47-48).

O fantástico também se revela na demasiada preocupação com a quantificação e na medida exagerada da altura da "porta fantástica" da casa da parteira $(3,99$ metros). O número três, por exemplo, aparece em várias passagens do livro (páginas $14,17,18,20,22,23,24,26,48,53,86,91,93,101,104,116,151,157,166$, 178, 190). Representação simbólica da união e da harmonia, o triângulo, segundo Chevalier (2003) é a primeira figura geométrica produzida por linhas retas, sendo um dos símbolos do sagrado. Ele denota as três esferas cósmicas, planos inferior, material e superior, e as três dimensões humanas, corpo, mente e espírito. Daí decorre a perfeição estabelecida com a triangulação entre as personagens Louca de Serrano, Fernanda/Genoveva e Filipa, cujo encontro, ao final do romance, promove o fechamento cíclico do tempo e da história. Justificada pela autora como forma de chamar a atenção do leitor para esta dimensão, a altura da porta pode estar atrelada à liberdade:

eu acho que o mundo tem que ir para a altura, para outros caminhos, para outras aventuras. E a largura, quanto à largura é o (espaço) que está no chão, em que a gente não precisa muito para estar no chão, a gente precisa muito para voar, mas pouco para estar no chão. (SALÚSTIO, 2009).

Liberdade que pretende ser alcançada por meio do discurso denunciativo, por vezes irônico, que percorre toda a obra e, em especial, as primeiras páginas, nas quais podemos conferir críticas à ignorância em relação às mulheres:

A jovem não teve direito a um tempo para dizer que não podia estar grávida porque desconhecia macho na sua natureza, ignorante das vezes em que algumas mulheres pelo mundo afora engravidam sem terem sido tocadas por macho, acabando por se conformar com os rótulos e rituais existentes para não incorrerem no desconforto incrédulo das demais criaturas. (SALÚSTIO, 1998, p. 11), 
As críticas também se estendem aos rituais,

[...] as águas da grávida recusavam rebentar, apesar da papa que foi obrigada a beber, feita com sangue de corvo e lama negra de uma fonte muito conhecida, solução segura para as situações de mulheres de águas preguiçosas, [...] (SALÚSTIO, 1998, p. 11).

Além deles, também é criticada a magia negra,

Inconfidências titubeadas por vozes coladas ao chão revelaram que a parteira que por algum tempo trocava do ofício de ajudar a dar à luz inocentes criaturas para ajudar rapazes a entrar com sabedoria no mundo adulto, ou ainda se entregava a actos de expurgar de males ruins a virilidade dos homens, pela certa, devia ter poderosas alianças com forças ocultas, tal o desfecho vitorioso de cada intervenção. (SALÚSTIO, 1998, p. 13-14).

E as diferenças socioculturais também são objeto da crítica,

O chefe deu ordem de retirada e decidiu que passasse a constar do relatório a ser apresentado superiormente que, da próxima vez que voltassem àquele fim de mundo, deveriam ser enquadrados por uma proteção policial porque os selvagens não ofereciam confiança [...] (SALÚSTIO, 1998, p. 20).

Espécie de lugar-personagem, Serrano é envolvida por uma atmosfera de suspense e mistério, principalmente em torno da gravidez de Fernanda - "Quem seria o homem que tinha engravidado Fernanda? Que prazer teria ele tido nos braços do pai de Filipa?" (SALÚSTIO, 1998, p. 100) -, cujas decifrações a esse respeito se realizam somente a nível de seu objeto (BARTHES, 1976), com a proposta exclusiva de reunir uma identidade fragmentada, de suscitar um nome que não existe, neste caso, o do pai biológico de Filipa.

Há indicativos que conferem à obra um caráter universal,

Esta é, sem dúvida, a lembrança de um tempo sem nome e sem história, como muitas que envolvem mulheres e homens em todas 
as épocas e lugares e asfixiam de tanto encanto, ou geralmente, de tanta impiedade. (SALÚSTIO, 1998, p. 26).

No entanto, Simone Caputo Gomes atenta-nos para a possibilidade de Serrano representar Cabo Verde:

Serrano, na pena, pincel ou câmera de Dina Salústio, uma povoação pequena, rural (de sol, chuva, sementeira, colheita), "fronteira de fronteiras", "pedaço de terra forte", de "pele lamacenta e alma rochosa", batida pelo "vento incansável"; de mulheres e crianças "improvisando o batuque em latas velhas", onde "uma cabra amamenta o bebê" e alguém "se afoga em grogue", evoca-nos um cenário já conhecido: Santo Antão e, por extensão, Cabo Verde. (GOMES, 2000, p. 277).

Esse aspecto também é evidenciado por Jorge Carlos Fonseca, que qualifica os nomes das personagens Bia e Maninha como muito comuns e típicos de Cabo Verde, além de citar a linguagem e a simbologia empregadas no encontro entre Maninha e Jerónimo e as características do clima da aldeia:

Jerónimo ter feito Maninha mulher na oficina do quintalão (haverá cena mais pressentidamente cabo-verdiana?!) ou a descrição do tempo da gente de Serrano: "era o sol, a chuva, as sementeiras e as colheitas ou qualquer outro que não viesse envolto em promessas que não decifravam [...]”. (FONSECA, 2013).

Em sua obra Questões de literatura e de estética (2010), Mikhail Bakhtin denomina cronotopo (do grego, cronos: "tempo"; topos: "lugar") a interligação das relações espaciais e temporais na literatura e sua indissociabilidade, constituindose como centro construtivo dos acontecimentos mais importantes do romance. $\mathrm{O}$ processo de absorção do cronotopo - do tempo, do espaço e do indivíduo histórico real que se mostra neles - contribui de modo substancial para que a narrativa adquira um caráter tangível. Em A louca de Serrano, a indissociabilidade entre tempo e espaço se dá por meio da interseção entre os espaços rural e urbano e da sequência de estágios temporais: a maldição de Serrano, o nascimento de Filipa, as festas que comemoram o final de 1994. São os espaços que mantêm latentes as marcas do tempo passado no tempo presente, graças à memória. 
A questão da nomeação, manifestada pelo episódio dos batismos da aldeia e da louca, merece um olhar mais atento. O batismo da aldeia, ordenado pela louca, que empresta sua voz à velha parteira, é fator desencadeador de sua própria nomeação. Dadas as afinidades semânticas entre a aldeia e a louca, o nome escolhido pela população para esta é Louca de Serrano, expressão metonímica que a identifica como parte (conteúdo) integrante do continente.

Carregar o nome da aldeia sem se sentir parte desta - revelada no desejo da Louca de encontrar "seu lugar" (SALÚSTIO, 1998, p. 33) - representa a perda de identidade, a mortificação do "eu"; significa receber um status natal que não pertence ao "eu" (DERRIDA, 2002), mas ao objeto, ao "outro".

$\mathrm{O}$ romance nos traz histórias de mulheres que enfrentam as agruras do destino reservado a elas. Mulheres como Filipa, que enxerga nos sete anos de mudez uma forma de resistência contra as adversidades da vida. O seu encontro com a palavra se faz pela descoberta da liberdade.

Mulheres como Fernanda (ou Genoveva), que enfrenta os preconceitos sociais e raciais, por eleger um homem negro e sem posses como seu companheiro:

Terá ainda lugar nestas páginas o registo de Filipa que, de acordo com aquilo que a avó materna contou para um advogado, carregava o nome como promessa feita pelo pai ao santo de sua devoção, San Martin, numa manhã que se prolongou por vários dias de gritos, confusão e incertezas sobre o sucesso de um parto dito prematuro. Filipa, uma menina amarrada no silêncio nos melhores anos de sua infância que, quando finalmente livre, não deixou que um dos seus lados de mulher tivesse voz. (SALÚSTIO, 1998, p. 26).

Como Gremiana, que, não se conformando com a procriação, destino reservado às mulheres, prefere a ausência de filhos, e acaba sofrendo as consequências por tal escolha. Sua voz tem como propósito o de expressar a loucura, a face visível da transgressão, a rebeldia e o inconformismo das mulheres que habitam a narrativa:

As mulheres mais velhas lembravam então que no meio das águas, a morrer, debatendo-se entre a corrente e as pedras e sabendo que já não podia ir a lugar nenhum de gente viva, Gremiana não suplicou, e gritou e voltou a gritar que os homens de Serrano eram uns animais hipócritas e covardes. Pedaços dos seus gritos berravam ainda que ela não daria nunca ao Valentim o prazer de lhe salvar o seu orgulho podre de homem a troco de ser coberta por macho que não desejasse. (SALÚSTIO, 1998, p. 73) 
E como Maninha, que, por ser estéril, carrega consigo as dores de pertencer a um mundo onde a fertilidade é símbolo da imobilidade e normalidade sociais:

Maninha consumia-se de inveja das companheiras que já tinham crianças e iludia-se a olhar para o pequeno baú com as roupas do bebé, ao qual juntou um saco de plástico enorme e uma caixa de papelão que dantes pertencera a uns sapatos [...]. Em todos aqueles anos de esperança falhada qualquer tostão que juntava era para o enxoval e nunca comprava um vestido ou uma saia para ela, porque - brevemente vou estar com barriga e nada me irá servir, sabe? e continuava a sonhar, a modificar as roupas e a lavar mais uma fralda, desencardindo-a do amarelo obsceno das marcas de um tempo sem uso, antes de a arrumar de novo. (SALÚSTIO, 1998, p. 54-55).

A tradição aparece na figura da parteira ("velha-velha"), detentora do saber e da transmissão deste; é ela quem inicia os rapazes na vida sexual e age como conselheira na cura de problemas com a libido:

[...] os braços e os dedos alongavam-se até entrar na carne e nos músculos, continuando pelo sangrento interno de cada homem que ela amassava e moldava até que nas suas poderosas mãos não sobrava nada, nem mesmo sombra de ideia mal definida que inviabilizasse a atividade sexual daquele que passara a soleira da sua porta de três metros e noventa e nove de altura por setenta e um centímetros de largo [...]. (SALÚSTIO, 1998, p. 13).

As histórias de vida dessas mulheres são observadas pela Louca, protagonista do romance, destinada a infinitas reencarnações e posta à margem da sociedade, por ser fruto de um incesto. Por visualizar na personagem atitudes de grandeza, o narrador enaltece sua história de vida, a fim de que o leitor se solidarize com ela:

Encontram-se aqui, sem dúvida, pedaços da vida da mulher que baptizou Serrano, conhecedora de todos os segredos do vale, origem desta breve narração, [...]; uma jovem que não encontrou homem, mulher, bandido ou animal que fosse, que a tivesse chamado filha, que a tivesse feito mulher e por isso, para se vingar, amaldiçoava as criaturas do lugar que, por cumplicidade, tinham torcido o seu destino e a conheciam por Louca de Serrano. (SALÚSTIO, 1998, p. 26). 
Embora não tenha uma aparência física determinada, nem se fixe a um espaço ou a um tempo real, "aparecia no povoado por artes desconhecidas para desaparecer do mundo visível dos vivos quando completava os trinta e três anos [...]. Depois voltava a aparecer, filha de gente nenhuma, de lugar e tempo nenhuns, criança, mulher." (SALÚSTIO, 1998, p. 26), a louca possui bem definida a idealização de um mundo distinto daquele que a cerca. Para alcançá-lo, dá voz aos seus ideais e grita, como o faz ao profetizar o fim apocalíptico da aldeia num imenso dilúvio trazido pelas águas da barragem.

Este tipo de manifestação insólita concede à loucura uma marca de animalidade, despojando a Louca do que nela "podia haver de humano" (FOUCAULT, 2008, p. 151), ao representar temor para a comunidade. Assemelha-se às chamadas bruxas renascentistas do Malleus maleficarum, constatando-se a singularidade de sua condição.

Ao lado dela (e, por vezes, confundindo-se com ela) aparece Filipa, mulher contemporânea, representante da geração feminina dos San Martín. Dentro do espaço em que o iletramento prevalece, os excertos narrativos da vivência entre Filipa e a Louca resgatam uma sabedoria outra, como nos mostra o episódio em que elas se encontram junto à fonte:

Um dia, junto da fonte, enquanto Filipa chorava a morte de um peixe, ela disse-lhe que a morte não dá sofrimento e que a única dor é alguém viver a vida que não lhe foi destinada, como ela própria vivia, cumprindo a maldição que caíra por si, quando um homem interrompeu o seu voo, ainda criatura no saco, em noite de Lua Nova, a caminho de sua verdadeira casa. Na hora em que Filipa deixava a aldeia, a jovem, parecendo mais atrapalhada do que nunca, disse-lhe que um dia seria feliz porque encontraria o seu lugar, apesar das centenas de luas que haviam de passar e dos imensos obstáculos que teria de vencer antes de achar o seu poiso. [...] (SALÚSTIO, 1998, p. 33).

Dotada da capacidade de perceber a realidade, a Louca exerce a função de sábia, revelando aquilo que não pode ser dito, ainda que não tenha o poder da enunciação, a exemplo do Príncipe Míchkin, de Dostoiévski, cujo dom intuitivo permite-lhe que enxergue a índole das pessoas, mesmo em sua idiotice.

Assim como Júlia, a quem o romance é dedicado, a Louca participa de uma loucura livre, que escapa ao tratamento, à psiquiatria, como tantas portadoras de transtornos mentais que vagueiam pelas ruas de Cabo Verde e do mundo. Mas dentro do espaço literário, a loucura da protagonista, metáfora da liberdade, 
aparece idealizada, revelando o desejo feminino em alcançar o inalcançável, em explorar o terreno recalcado da mente.

\begin{abstract}
:
The female literature in the post-colonial societies is considered by Gayatri C. Spivak as a process of metonymic saga of women used as a complaint instrument, which allows the myths and the prejudices failure a long time reinforced by the patriarchal discourse. Among the women who found her voice and spoke up, no longer considered as only native informants of oral histories of their culture deserve mention the Cape Verdean Dina Salústio, Vera Duarte, Fátima Bettencourt, Orlanda Amarilis and Dulce Almada Duarte. The objective of this paper is to investigate in Dina Salústio's novel A louca de Serrano, how the insanity theme is built, represented by the african woman (and character) Louca de Serrano, which can be understood as a voice full of loneliness, pain, denial, rebelliousness and nonconformism and as a resistance mark to the women marginalization into and by the hegemonic social practices.
\end{abstract}

Keywords: Dina Salústio. A louca de Serrano. Women marginalization. Resistance.

Referências:

AAVV. Mirabilis de veias ao Sol: Antologia dos novíssimos poetas caboverdianos. Lisboa; Praia: Caminho; Instituto Caboverdiano do Livro: 1991.

ADORNO, Theodor W. Notas de literatura I. Trad. Jorge de Almeida. São Paulo: Duas Cidades; Editora 34, 2008.

ALMADA, José Luís Hopffer. A louca de Serrano, de Dina Salústio. In: Jornal A Semana. Praia, 2007.

BAKHTIN, Mikhail. Questões de literatura e de estética. São Paulo: Hucitec, 2010.

BARTHES, Roland. Aula. Tradução de Leyla Perrone-Moisés. São Paulo: Cultrix, 2010.

BARTHES, Roland. Crítica e verdade. Tradução de Leyla Perrone-Moisés. São Paulo: Perspectiva, 2003. 
BARTHES, Roland et al. Masculino, feminino, neutro: ensaios de semiótica narrativa. Trad. Tania Franco Carvalhal. Porto Alegre: Globo, 1976.

BENJAMIN, Walter. Magia e técnica, arte e política: ensaios sobre literatura e história da cultura. Tradução Sérgio Paulo Rouanet. São Paulo: Brasiliense, 1994.

CABO VERDE. Plano Nacional de Desenvolvimento Sanitário 2008-2011. Praia: Ministério da Saúde, 2008.

CABO VERDE. Plano Nacional de Desenvolvimento Sanitário 2012-2016. Vol. I. Praia: Ministério da Saúde, 2012.

CHEVALIER, Jean; GHEERBRANT, Alain. Dicionário de símbolos. Tradução de Erlon José Paschoal. Rio de Janeiro: José Olympio, 2003.

CLÉMENT, Catherine; KRISTEVA, Julia. Entre o feminino e o sagrado. Tradução de Rachel Gutiérrez. Rio de Janeiro: Rocco, 2001.

COQUERY-VIDROVITCH, Catherine. Les africaines. Histoires des femmes d'Afrique noir du XIX au XX siècles. Paris: Éditions Desjonquères, 1994.

DERRIDA, Jacques. Torre de Babel. Tradução de Júnia Barreto. Belo Horizonte: Editora da UFMG, 2002.

DIAS, Maria Odila Leite da Silva. Novas Subjetividades na Pesquisa Histórica Feminista: uma hermenêutica das diferenças. In: Revista de Estudos Feministas. Rio de Janeiro, n. 2, v. 2, p. 273-285, 1994.

DOSTOIÉVSKI, Fiódor. O idiota. Tradução de Paulo Bezerra. São Paulo: Editora 34, 2002.

FORTES, Corsino. A cabeça calva de Deus. Lisboa: Publicações Dom Quixote, 2001.

FOUCAULT, Michel. História da loucura na Idade Clássica. Tradução de José Teixeira Coelho Neto. São Paulo: Perspectiva, 2008.

GOMES, Simone Caputo. A louca de Serrano, de Dina Salústio. In: Revista Metamorfoses. Cosmos/Cátedra Jorge de Sena - UFRJ. Lisboa, 2000, p. 277-281. GOMES, Simone Caputo. Cabo Verde: literatura em chão de cultura. São Paulo: Ateliê Editorial, 2008.

GOMES, Simone Caputo. Echoes of Cape Verdean Identity: Literature and Music in the Archipelago. In: LEITE, Ana Mafalda (Org.). Cape verdean: language, literature \& music. Dartmouth: Portuguese Literary \& Cultural Studies, University of Massachusetts Dartmouth, 2003, p. 273-275. 
GRASSI, Marzia. A questão do género no sector informal em Cabo Verde: um estudo sobre as "rabidantes" do mercado "Sucupira" na Ilha de Santiago. In: Africana Studia. Edição da Faculdade de Letras da Universidade do Porto. Porto, n. 4, p. 7-32, 2001.

LABAN, Michel. Cabo Verde: encontro com escritores. Porto: Fund. Eng. António de Almeida, 1992.

LOPES, Baltasar. A caderneta. In: Antologia da ficção cabo-verdiana contemporânea: António Aurélio Gonçalves, Baltasar Lopes, Francisco Lopes, Gabriel Mariano, H. Teixeira de Sousa, Jorge Barbosa, Manuel Lopes, Pedro Duarte, Virgílio Pires. Edições Henriquinas, Achamento de Cabo Verde: 1960, p. 113-122.

MATA, Inocência L. S. e PADILHA, Laura Cavalcante. A mulher em África: Vozes de uma margem sempre presente. Lisboa: Colibri/Centro de Estudos Africanos - FLUL, 2006.

MENDES, Domingos Veiga. Perspectivas e alternativas para a economia de Cabo Verde. 2010. 156f. Dissertação (Mestrado em Economia do Desenvolvimento) - Faculdade de Ciências Econômicas, Universidade Federal do Rio Grande do Sul, Porto Alegre, 2010.

PEREIRA, Érica Antunes. De missangas e catanas: a construção social do sujeito feminino em poemas angolanos, cabo-verdianos, moçambicanos e são-tomenses. 2010. 271f. Tese (Doutorado em Estudos Comparados de Literaturas de Língua Portuguesa) - Faculdade de Filosofia, Letras e Ciências Humanas, Universidade de São Paulo, São Paulo, 2010.

SALÚSTIO, Dina. A louca de Serrano. Praia: Spleen Edições, 1998.

SALÚSTIO, Dina. Entrevista concedida a Genivaldo Rodrigues Sobrinho. Praia, dezembro de 2009.

SALÚSTIO, Dina. Entrevista concedida a Simone Caputo Gomes. Praia, novembro de 1994.

SANTOS, Maria Emília Madeira et al. (Org.). História concisa de Cabo Verde. Lisboa - Praia: IICT - IIPC, 2007. 
Webgrafia:

CABO VERDE. Código Civil (1967). Portaria $n^{\circ} 22.869$, de 4 de Setembro de 1967.

Disponível em: http://www.rjcplp.org/sections/informacao/anexos/legislacaocabo-verde4919/codigos-e-estatutos-cabo 1752/codigo-civil-cabo-verde/ downloadFile/file/cabo_verde_codigo_civil.pdf?nocache $=1365701924.63$. Acesso em 11 jun. 2013.

CABO VERDE. Constituição da República de Cabo Verde (1980). Na versão dada pela Lei Constitucional n. 1/V/99, de 23 de Novembro. Disponível em: http:// www.mj.gov.cv. Acesso em 12 jun. 2013.

CABO VERDE. Plano Nacional de Luta Contra a Pobreza (1988/1989). Disponível em: http://www.governo.cv/index.php?option=com docman\&task=doc_download\&gid=38\&Itemid=91. Acesso em 13 jun. 2013.

CABO VERDE/ONU. Objectivos do milénio para o desenvolvimento (2008). Disponível em: http://www.un.cv/omd.php. Acesso em 18 jun. 2013.

FONSECA, Jorge Carlos. A louca de serrano: o percurso de um inesperado e ingénuo mergulho ou as loucas confissões de um leitor. Disponível em home.no/ caboverde/dinasalustio.doc. Acesso em 09 jul. 2013.

ICIEG. História do ICIEG. Disponível em: http://www.icieg.cv/article/3. Acesso em 12 jun. 2013.

INE/ICIEG/ONU. Mulheres e homens em Cabo Verde: fatos e números 2008. Disponível em: http:/www.ine.cv/actualise/publicacao/files/15c06ce8-51664607-ab90-1e914bc4235aMulheres\%20e\%20Homens\%20em\%20Cabo\%20 Verde.pdf. Acesso em 13 jun. 2013.

INE/ICIEG/ONU. Mulheres e homens em Cabo Verde: fatos e números 2012. Disponível em: http://www.ine.cv/actualise/publicacao/ files/1103929942013Mulheres\%20e\%20Homens\%20em\%20Cabo\%20Verde. pdf. Acesso em 17 jun. 2013.

VARELA, Bartolomeu L. O sistema eleitoral cabo-verdiano e o papel da comunicação social no âmbito das eleições. In: SEMINÁRIO DE FORMAÇÃO DE JORNALISTAS, 2011, Praia. Texto de apoio. Disponível em: www. academia.edu/769540/O_Sistema_Eleitoral_Cabo-verdiano_e_o_papel_da_ Comunicalcao_Social_no_ambito_das_Eleicoes. Acesso em 16 maio 2013. 


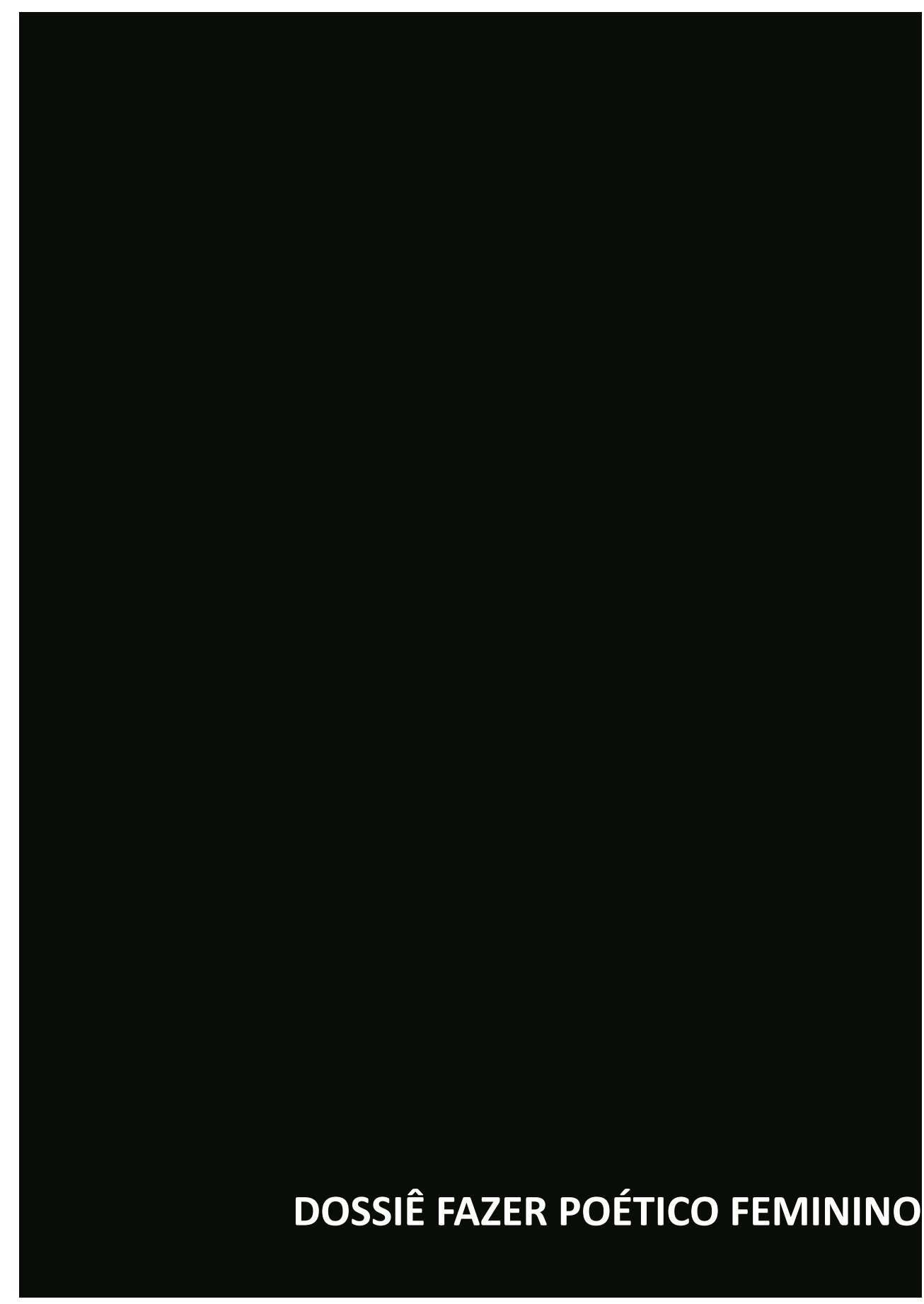


